\title{
Relato de Experiência: acompanhamento de uma criança em consulta de Enfermagem na Atenção Primária à Saúde
}

\author{
Camilla Alves de Souza
}

\begin{abstract}
Resumo
A consulta de enfermagem de puericultura é uma prática diária à Atenção Primária à Saúde. Nela, as inserções dos parâmetros antropométricos nas curvas de crescimento constituem um importante instrumento técnico para monitorar o crescimento e desenvolvimento das crianças e dos adolescentes. Segundo o Ministério da Saúde, o peso relacionado com o comprimento representa o melhor indicador de crescimento da criança. Com isso, podemos avaliar durante a consulta de enfermagem diversos agravos à saúde detectados a partir da antropometria como: desnutrição, sobrepeso, obesidade e condições associadas ao crescimento e nutrição da criança. E podendo ser precocemente compartilhados com o Núcleo de Apoio à Saúde da Família (NASF) ou se necessário encaminhadas para avaliação de um especialista. Descrever a importância do acompanhamento antropométrico durante a Consulta de Enfermagem de Puericultura na Atenção Primária à Saúde no Município do Rio de Janeiro. Estudo de caso. TMT, 04 anos, comparece a Unidade acompanhada da cuidadora a qual se queixa de lêndeas em couro cabeludo, prurido anal e da resistência à alimentação que a criança apresenta. Avaliação antropométrica: Altura: 100(cm)|Peso: 15(Kg)|IMC: $15,00 \mathrm{Kg} / \mathrm{m}^{2}$. Classificação: peso adequado; Estatura: adequada; e IMC adequado para a idade segundo Estatura/Idade, de acordo com as curvas de crescimento da OMS (2007) para crianças de 0 a 5 anos e IMC, de acordo com as curvas de crescimento da OMS (2006), porém no limite da inferior do escore. Neste primeiro encontro foram tratadas as necessidades clínicas, prescrito o uso do sulfato ferroso, o vermífugo, realizadas orientações sobre a higiene dos alimentos, os hábitos alimentares da família. Após quinze dias, identificou-se a permanência da dificuldade do ganho de peso. Havendo então, a pactuação do atendimento junto à nutricionista do NASF. A partir do empenho da cuidadora e das orientações elaboradas nas interconsultas com o NASF como: o uso de sulfato ferroso, a inserção de frutas, a restrição de alimentos industrializados, a regularização dos horários para as refeições, a limitação de lanche nos intervalos, a introdução de 01 colher (sopa) de óleo nas grandes refeições junto ao feijão obteve-se o ganho de peso da usuária, e a saída do valor limítrofe da relação peso/atura curva antropométrica: Altura: 102(cm)|Peso: 15,700(Kg)|IMC: 15,70 $\mathrm{kg} / \mathrm{m}^{2}$. Sabe-se que após os dois anos de idade, há diminuição do ritmo de crescimento, do apetite e por consequência uma menor necessidade de ingesta calórica. Para tanto, é fundamental que o profissional esteja atento à demanda nutricional das crianças, já que, esta fase é imprevisível, e se conduzida inadequadamente poderá causar distúrbios alimentares e gerar consequências posteriores. Dessa forma, a consulta de enfermagem além das demandas clínicas, buscou por meio da clínica ampliada o cuidado centrado na pessoa, estimulando a construção da autonomia e do autocuidado da cuidadora com a criança de modo a proteger alterações passíveis de modificação que possam repercutir em sua vida adulta.
\end{abstract}

Descritores: Puericultura, Antropometria, Interconsulta. 